\title{
I BELIEVE THAT HE DIDN'T DO IT AND I DON'T BELIEVE THAT HE DID IT. THE INFLUENCE OF CONTEXT ON THE SEMANTIC-COMMUNICATIVE RELATIONS BETWEEN SENTENCE NEGATION AND PERFORMATIVE NEGATION
}

\begin{abstract}
The subject matter of the paper is an analysis of the semantic relations between sentence negation, performative negation, and declarations in reference to utterances which speech acts theory gives the label of representatives. Apart from linguistic-semantic analyses, empirical studies have been conducted on the manner in which sentence negation and performative negation are processed. The results of Study I demonstrate that the semantic relation between sentence negation and performative negation changes depend on the type of comment (positive vs. negative), and contextual factors (type of expectations towards events being commented on). As it turned out, when the situational context suggests a negative comment by the sender, participants offer similar interpretations of utterances with sentence negation and performative negation. In Study II the participants assessed the likelihood of the occurrence of the facts spoken of by a sender who uses sentence negation or performative negation. In a context suggesting positive utterances by the sender, a clear difference emerged between sentence negation and performative negation. This difference was not present in respect of negative expectations. The results achieved confirm the assumptions of the model of conversational inference regarding the influence of context on interpretation of a message. The recorded results indicate the semantic relations between declarations, sentence negation, and performative negation, which change depending on the affective significance of the message and contextual factors.
\end{abstract}

Keywords: speech acts, performative negation, sentence negation, verbal politeness, representatives.

\section{Introduction}

The phenomenon of negation is an object of interest in various scholarly disciplines, including philosophy, logic, linguistics, psycholinguistics, 
and cognitive psychology. Negation is also an important element of everyday communication, in which it performs a diverse array of functions. The most important of them include the corrective-logical and volitional functions. The former refers to questions of truth and falsehood. It should be emphasized that, traditionally, negation - both in logic and in natural language - has been described through reference to the concepts of truth and falsehood (see Wason, 1972, Maciuszek, 2006). For example, Bertrand Russell (1992) linked negation of a sentence with a declaration of its falsity; if $p$ is a sentence, the expressions " $p$ is false" and "not $p$ " are synonyms. In everyday communication, the logical-corrective function of negation consists in the reversal of meaning, declaration of falsity of someone's utterance, correction of statements, contradiction of something. (Not true, Galileo did not work together with Copernicus). In turn, the volitional function of negation emerges when we express disagreement, refusal, or objection, when we forbid something (Smoking is forbidden), and also when we suggest specific behaviours and relations (Don't worry). Additionally, in everyday communication one of the primary functions of negation is to inform of the absence of something; of certain objects or events (e.g. There is no washing machine in the house).

There are many types of expressing negation (see Dahl, 2011). A distinction is drawn between asserted and non-asserted negation (Clark, 1976), which is termed explicit and implicit negation, respectively. It is obvious that no, not, never constitute explicit negation. Implicit negation is constituted by pragmatic inferences and is connected e.g. with the words forget, fail, doubt (Xiang et. all, 2016, see also Fodor, Fodor, and Garrett, 1975). Within explicit negation, a distinction is drawn between morphological (affixal) negation and sentence negation.

In this paper I explore two cases of explicit negation; sentence negation and performative negation. Sentence negation concerns the content of a judgement, and frequently occurs in the description of events and behaviours; particularly when we want to communicate that something has not happened or has not been done (e.g. John didn't come to work this morning). Performative negation consists in the negation that we are doing something through speech (e.g. I am not asking you for help), as well as the negation that we are speaking about something (e.g. I'm not saying that he's a thief). The main object of the work is an analysis of semantic relations between sentence negation and performative negation in the case of utterances which are termed in speech acts theory as representatives. Semantic analyses indicate different meanings between sentence negation and performative negation in different speech acts (e.g. I promise I won't 
say anything vs. I don't promise I will say something). However, the conception of conversational inference assumes that the sense of a message results not only from the mere linguistic meaning of the utterance, but also from context. I have posed the question of what kind of influence selected contextual factors will have on the processing of sentence negation and performative negation referring to the first type of speech act as classified by J. Searle, that is, representatives. The search for answers has been based on experimental studies.

Let us add that empirical studies on processing of negation have led to several fundamental discoveries. Firstly, negated sentences are more difficult to process than affirmative ones (greater difficulty in understanding, inference, recollection). Secondly, at an earlier stage of processing, the negated state of affairs is frequently activated (see Tian, Breheny, 2016). Thirdly, the use of negation can lead to counterproductive effects, meaning reactions inconsistent with the intention of the sender. For example, studies have demonstrated that a negated order such as Don't get upset or Don't pay attention to those mistakes can paradoxically lead to precisely the opposite effects (Maciuszek, 2013).

The processing of performative negation has not previously been the subject of serious study grounded in the methodology of empirical sciences. This work combines semantic analyses with an attempt at empirical verification of the predictions that result from the relevant theory. At the beginning, I include an introduction to the issue of speech acts; in their context, analysis is undertaken of the phenomenon of negation, and a presentation is made of semantic aspects of performative and sentence negation in a selected speech act (representatives). The own studies presented address the manner of interpretation of utterances depending on linguistic data (forms of the message) and contextual factors.

\section{Speech acts, sentence negation, and performative negation}

Language as a system of signs is a tool for constructing a representation of the world (presentation of objects), and a tool for communication (exchange of information between a sender and a receiver). John Austin (1962) pointed out that language serves not only to describe reality, but also to create it and to perform certain acts. Many utterances constitute the practice of a particular action: for example, when the sender apologizes, forgives, thanks, congratulates, offers condolences, announces a verdict, etc., he or she is engaging in a certain deed whose constituent element is a partic- 
ular utterance. In this manner, Austin drew attention to the performative (executive) function of speech; this is the function referred to by "speech acts". Speech acts concern various activities and intentions of the sender, fulfilled by speaking.

\subsection{Types of speech acts}

Searle (1975) distinguished five categories of speech acts: 1. Representatives - the sender's objective is to communicate his recipient's conviction on a given subject, to express her or his belief as to the truth of what she or he is saying. These include descriptions, classifications, explanations, predictions, and negations. 2. Directives - the objective is to induce the recipient to behave in a manner consistent with the content of the directive. This category includes recommendations, orders, requests, and questions. 3. Commissives - the sender undertakes an obligation towards the receiver to do something (by way of a promise, contract, guarantee). 4. Expression - the intention of the sender is to express feelings and attitudes towards someone/something. These types of speech acts include apologies, thanking, congratulations, greetings, condolences, wishes. 5. Declarations, Verdictives - these can give rise to particular factual circumstances in social situations (e.g. a court verdict) or announce a given set of circumstances as officially enacted (e.g. the decision of a football referee).

\subsection{Performative verbs}

Indicators of the type of speech act are so-called performative verbs, which constitute the name of the behaviour performed via speech. The list of performative verbs compiled by Austin includes verbs like state, say, inform, order, ask, promise, swear, congratulate, apologize, nominate, announce, etc. A speech act can be performed explicite or implicite. The sender, in using performative verbs, may directly indicate the type of speech act being done, that is, the behaviour being performed through speech (I swear I'll never forget you. I wish you good luck. Please do that. I order you to leave!). However, performative verbs need not appear in the surface structure of an utterance; indicators of the type of speech act may include the order of words, accent, intonation, mode of the verb, situational context, etc.

\subsection{Performative negation and sentence negation}

Within the structure of an utterance, we distinguish the content of a judgement and an intention expressed implicite or through performative verbs; for example, I promise I'll give the money back. In this example, the performative verb I promise indicates explicite the type of speech 
act being performed; in this case it is a promise (the sender's obligation to do something). Negation can concern the content of the judgement (e.g. I promise I won't give the money back), or can concern the performative verb (e.g. I don't promise I'll give the money back). In the first case, we are dealing with sentence negation, while in the second it is performative negation. Performative negation is a refusal to fulfil a linguistic act of a given type, for example a declaration, congratulation, promise, request, apology, swear, etc. (I'm not declaring, I'm not congratulating, I'm not promising, I'm not asking you, I'm not apologising, I'm not swearing, etc.); it therefore concerns performative verbs. Utterances can thus contain double negation; performative and sentence simultaneously (e.g. I'm not promising that I won't tell anyone. I'm not saying that I won't come). In our semantic analyses and empirical studies we are examining one speech act: representatives.

\subsection{The functions of sentence and performative negation in representatives}

One type of speech act is representatives (also referred to as declarations, ascertainment, announcements). They are utterances subject to evaluation in categories of truth/falsehood, and the sender - in transmitting some information to the receiver - expresses his conviction as to the veracity of what he is saying. The sender may make a categorical statement, or may "consider", "suspect", or "doubt". Representatives generally do not contain a performative verb in their surface structure (we usually say, for example: They work in the school or Paul lives in the mountains rather than I think they work in the school or I inform you that Paul lives in the mountains). In declarations, performative verbs most frequently serve to let the sender emphasize that she or he is the author of the statement (I claim, I say), to express her own convictions about an expressed opinion or state of knowledge (I think, I feel, I know that, etc.), or to emphasize the intention to communicate information ( I inform, I declare).

Sentence negation concerns the content of an opinion; as regards representatives, it is visible in a description of events or behaviours, particularly when we wish to communicate that something has not occurred or was not done (e.g. John didn't come to work today. It didn't rain yesterday). Sentence negation frequently performs a corrective function; we apply it when we judge that someone is mistaken (e.g. That's a mistake; he didn't do that). As Wason (1965) observed, we employ negations particularly when we want to call into question that which is consistent with expectations, or what usually occurs. The declaration This train will not be late today is more 
justified if it usually is late; in this manner, negation corrects the mistaken expectation that the train will be late this time as well.

In turn, performative negation in the type of speech act under consideration here is generally used when we assume a mistaken assessment of our knowledge, an incorrect understanding of our intentions on the part of the receiver, when we wish to refrain from stating our opinions on a given subject (e.g. I'm not saying that he did that. I don't know who did that. I don't think she has a problem with the law).

\section{Representatives. Semantic relations between performative negation and sentence negation, and contextual factors}

Interesting semantic issues arise when we consider the logical function of negation. First and foremost, emphasis is placed (see: Lyons, 1989) on the semantic differences between negation in speech acts and negation in twovalued logic. In propositional calculus, $\sim$ p signifies both assertion of a negative sentence (It is true that not $p$ ), and as negation of a positive statement (It is not true that $p$ ). However, in speech acts, negation of a performative verb transmits a different meaning than negation of a complement (e.g. I am not apologising for coming vs. I apologise for not coming). The use of double negation in these two cases also has a different semantic effect. In propositional logic, the law of double negation applies, which says that two negations in a sentence cancel each other out, and thus such a sentence is of an affirmative character $(\sim(\sim \mathrm{p})=\mathrm{p})$. In natural language as well a double negation can form an affirmative sentence (It's not true that she didn't pass the exam is the same as She passed the exam). However, in respect of speech acts a double negation (performative and sentence) produces a different effect than in the case of propositional logic (I'm not apologising for not coming has a different meaning than I'm sorry that I came).

Let us pay attention to the semantic aspects of using negation in speech acts, that is, in everyday communication. In many types of speech acts we may easily perceive semantic differences between a statement with sentence negation and one with performative negation. For example, (1) I don't promise that I will come to the meeting has a different meaning than (2) I promise I will not come to the meeting. Utterance (2) constitutes a promise to refrain from doing something, while utterance (1) is a declaration of refusal to make a promise. The semantic differences between sentence and performative negation can be observed in the case of various types of acts, such as: (3) I apologise for not coming (sentence negation) 
vs. (4) I don't apologize for coming (performative negation); (5) I congratulate you for not losing vs. (6) I don't congratulate you for losing. (7) I'm not asking you to do that vs. (8) I'm asking you not to do that.

In the case of representatives, that is, utterances which can be evaluated in terms of truth/falsehood, we can also observe a semantic difference between an utterance with performative negation and sentence negation; for example, I am not saying that rain is falling means something different from I'm saying that rain is not falling or I don't know if he is right vs. I know he is not right. However, in the case of some performative verbs related to declarations, such as believe or think, it is not always easy to distinguish performative negation from sentence negation. Indeed, the very same utterance can be coded as performative negation or as negation concerning a judgement (sentence negation). The sentence $I$ don't think that he went to work can involve performative negation: It is not true that I think he went to work, or sentence negation: I think that he did not go to work. A similar case is when we replace I think with I believe or I feel. I don't believe that he said that can mean It is not true that I believe he said that, or I believe that he did not say that. Such examples demonstrate how utterances containing negations can lead to mistakes in the process of communication.

\section{Study I}

The various semantic subtleties associated with processing performative negation have not previously been at the centre of scholarly attention, neither in the Polish nor international literature. The objective of experiment 1 is to study the semantic relation between performative negation, sentence negation, and statements; in particular, to determine whether performative negation is perceived as refraining from judgement (information about not taking a position), or also as negation of the content of the judgement. The conception of conversational inference assumes that the sense of a statement results not only from the simple linguistic meaning of the utterance, but also from the context, which can be determined by the expectations of those participating in the discourse. This is why I have also examined whether the interpretation of various forms of utterances depends on expectations towards the person commenting on the events (positive vs. negative expectations) and on the type of comment (positive vs. negative).

In these studies I used a "scenario paradigm"; participants received short descriptions of various situations in which the heroes of stories expressed comments formulated in different ways - using declarations, sen- 
tence negation, and performative negation. For example, the comments appended to one story were "I think it was boring", "I don't think that it was boring", "I think that it wasn't boring". Half of the scenarios presented events in which it could be expected that they would be positive, that is, that the sender would supply a positive comment, and half of them suggested a negative meaning. What follows is a sample scenario with a positive expectation and one of four possible comment versions. We placed a 7-point scale underneath the scenario, and it was the participant's task to judge what, on that scale, the hero had in mind (the extreme values of the scale are occupied by the poles of a given antonymy).

John spent the evening with his new love interest. The next day a friend asked him how the evening went. John answered:

"I don't think that it was boring."

$$
\text { very boring } 1234567 \text { very interesting }
$$

The scenarios concluded with a value judgement from the hero, which came in the form of either an affirmative, or sentence negation, or performative negation (using the performative verb "I think"). It also had various affective meanings: positive vs. negative (e.g. I think it was good; I think that it wasn't good; I don't think that it was good). The sender's comment contained the pole of a given antonymy: either adjectival or adverbial. It was the task of the participants to judge on a 7-point scale what the sender had in mind when presenting a given judgement (the poles of each antonymy were defined affectively, and thus we examined how participants interpreted a given utterance in the positive-negative dimension). What follows is a sample scenario with a negative expectation and one of four potential comment versions:

After returning from a trip abroad, Anne had to carry her own bags up three flights of stairs. When some of her co-workers asked her about the weight of her bags, Anne responded:

"They were heavy"

$$
\text { very heavy } 1234567 \text { very light }
$$

In other words, the objective of the experiment was to examine the manner in which an utterance was interpreted depending on its form (affirmative vs. sentence negation vs. performative negation), its meaning (positive vs. negative comment), and expectations towards the event being commented on (positive vs. negative).

The results demonstrated that interpretation of messages is influenced by the contextual factor in the form of expectations; when the scenarios pre- 
sented events following which it could rationally be expected that they would turn out positive (that the sender would utter a positive comment), the participants assigned the utterances a higher level of positivity (or lower level of negativity when the utterance had a negative meaning) when compared to a situation in which the description contained in the scenario suggested a negative comment from the sender.

It also turned out that the type of expectations (positive vs. negative) influenced the semantic relations between performative negation and sentence negation. When the described situation suggested positive expectations towards the comment, sentence negation provoked a more polar assessment on the positive-negative dimension. In the case of positive comments, utterances with sentence negation (e.g. I think that it wasn't bad) were judged as expressing greater positivity than performative negation (e.g. I don't think that it was bad). In turn, when it comes to negative utterances with sentence negation (e.g. I think that it wasn't interesting), these were judged as expressing more negativity than with performative negation (e.g. I don't think it was interesting). On this basis we may say that the message in performative negation was perceived more as refraining from judgement rather than expression of a judgement concerning the situation.

Nevertheless, concerning the interpretation of negative comments on situations involving expected negative consequences, there was no difference between performative negation and sentence negation; comments expressed using performative negation were interpreted similarly to comments expressed in the form of sentence negation. In other words, those two forms of utterances were perceived as demonstrating the same level of affective meaning.

It would seem as though this result can be explained by the phenomenon of verbal politeness. As Colston (1999) observes, an expression of verbal politeness may be avoidance - while desiring to present a negative judgement - of directly negative words (because the receiver may perceive such an utterance as impolite) as well as the use of negated positive terms (instead of bad we can say not good). The receiver assumes verbal politeness in the utterance of the sender, particularly when the sender is discussing a situation about which we may expect a negative comment. When the sender uses performative negation, speaking of a situation about which we may expect a negative comment, the assumption of the sender's verbal politeness induces the receiver to interpret that utterance as if it referred to a situation rather than the intentions of the sender. When the question How was your conversation with your mother-in-law? is answered with I don't think it was nice, we can interpret this response as a negative judgement about 


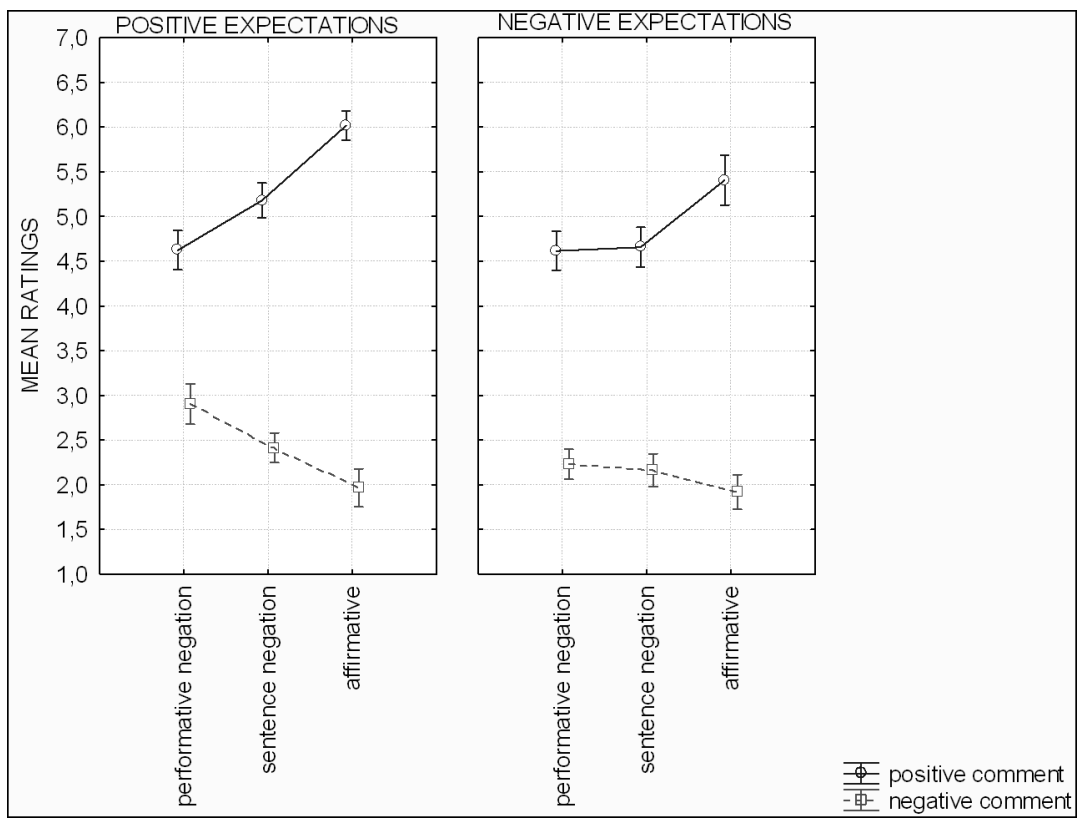

Figure 1. Intended meaning rating for affirmative, performative negation and sentence negation

the situation rather than the sender refraining from judgement on that subject, which boosts the negative load of that utterance. These remarks concern the negative meaning of the utterance. However, positive comments expressed in the form of performative negation were interpreted in a similar manner regardless of the type of expectation. We may thus risk the suspicion that the sources of the potential semantic identity of performative negation and sentence negation are contextual factors and the phenomenon of verbal politeness.

In summary, an important objective of these studies was to perform a semantic comparison between sentence negation and performative negation, and a judgement as to whether negation of a performative verb is perceived as the sender refraining from passing judgement, or is understood as sentence negation (concerning the content of the judgement). It turned out that the manner of interpretation of the comment expressed through performative negation depends on the situational context to which the utterance refers, but also on the meaning of the message (positive vs. negative). The results of these studies confirm the assumptions of linguistic pragmatics - interpretation of an utterance depends not only on linguistic variables (meaning of a sentence), but also on contextual factors, that is, on the events a given utterance refers to (events of a positive or negative sense). 
"I believe that he didn't do it" and "I don't believe that he did it"...

\section{Can sentence negation and performative negation be a tool in the creation of subtext?}

\subsection{Sentence negation and creation of subtext}

Marek Tokarz (2006, pp. 60-61) cites an anecdote that illustrates quite well the manner in which allusive content or insinuations can come about. The captain of a ship wrote in his log: Today, 23 March, the first officer was drunk. The next day the first officer was on watch, and in the same log he wrote: Today, 24 March, the captain was sober. In the captain's notebook there is a tremendous amount of information, which may be surprising, but this is precisely the reason for which this sentence comes as no surprise and does not induce us to seek any subtext. In the case of the first offer's entry, the literal wording is predictable and trivial, which is why its presence may provide pause to think; first and foremost, the question may arise with the receiver of what is so unusual or significant in the fact that the captain was sober that day that such information was recorded in the ship's log.

Here the question arises of whether a similar effect can be achieved by using negations to confirm something that would seem to be obvious. As mentioned previously, the natural function of negation is to correct a conviction or expectation. The announcement that Smith was not late to work today is more justified if he is usually late; in this manner, the negation corrects the mistaken expectation that Smith was late this time as well. The question arises of how we interpret a message in which negation is intended to confirm what we felt to be obvious. Let's imagine that we are reading a newspaper headline Parents of secondary school pupils did not come to blows during parent-teacher conferences. In this case, is the function of negation similar to the function that emerges in information concerning the famously tardy Smith? Tokarz (2005) claims that negation can be one of the mechanisms for generating subtext. He observes that the more surprising an event is described by the sender, the lesser the degree to which the receiver seeks a subtext. If the overt content is sufficiently interesting, exceptional, or new, then we are unlikely to seek hidden meanings. If we were to read a headline Rector of the local university arrested then we would certainly be interested, surprised, and inclined to learn more. On the other hand, we would not seek out hidden meanings, asking what the journalist had in mind; indeed, the most likely thing is that she had in mind precisely what she wrote. The situation will be similar when negation is used; if we read on the sports page that Ultras of opposing teams not allowed to confront one another, then we will treat 
this message literally. Indeed, the negation performs the natural function mentioned previously of calling into question that which could be expected. The situation would be different if the headline read Rector of local university not arrested. Such a negating announcement would confirm a certain obvious fact: that rectors are generally not arrested. And this may lead the reader to ask the question of why such information was given, what is underneath? The use of negation in order to confirm what seemed obvious to us can create a subtext; in other words, the receiver may assume that the message says more than just what is contained at the level of its literal content. And thus, the likelihood of seeking subtexts grows when we read something obvious, banal, not even worthy of mention. These examples indicate the insinuative potential to be found in the invocation of negations.

\subsection{Persuasive aspects of performative negation}

Can performative negation create an insinuative subtext? If the receiver hears the comment I'm not saying that Reggie stole that car, will he then think that Reggie is a suspect? He will certainly understand that a car was stolen, and also that some people might suspect Reggie of stealing it. The following things support the insinuative potential of performative negation: firstly, consistent with the two-step simulation account of negation processing (Kaup, Lüdtke and Zwaan, 2006), a negated message may evoke associations consistent with the core of the message. Secondly, a dissociation error is likely to arise, that is, losing the sign of negation, which can lead after a time to errors in recollection. Thirdly, refusing to pass judgement may lead the receiver to perceive the sender as objective. As demonstrated in studies by Walster, Festinger (1962), people are more susceptible to the persuasion of messages which they do not perceive as being prepared with a view to exerting influence; messages expressed incidentally, without the intent to exert influence, are considered to be objective and unbiased. It thus results that the trustworthiness of the sender of a message increases when receivers are convinced that the sender is not trying to influence them. Fourthly, the processing of complex sentences, as well as of negation, requires more time and cognitive resources (Clark and Chase, 1972). Studies (Festinger and Maccoby, 1964) indicate that a receiver is more susceptible to persuasive message when her attention is being loaded. These arguments attest to the existence of the persuasive influence of performative negation. The objective of the study that we present below was to check those predictions. 
"I believe that he didn't do it" and "I don't believe that he did it"...

\section{Study II}

Two experiments were conducted with similar designs: participants received a list of nine sentences concerning a politician named Brown, a candidate in elections to the City Council. They were told that the sentences came from an interview given to a newspaper by another politician, Johnson. In experiment 1, participants were informed that the sender was speaking about a political competitor standing for a seat in the same electoral district. In the second experiment, the sender spoke of a fellow party member from another electoral district. Among these nine sentences there were two key sentences concerning issues of corruption and problems with alcohol on the part of Brown. Depending on the group, these sentences took different grammatical forms: 1. Affirmative (He takes bribes. He has a problem with alcohol). 2. Sentence negation (He does not take bribes. He does not have a problem with alcohol), 3. Performative negation (I am not saying that he takes bribes. I am not saying that he has an alcohol problem). The remaining sentences are neutral ones concerning the professional-private.

After reading through the list of these utterances, the participants judged the probability that Brown takes bribes and has an alcohol problem. The objective of the study was to determine the degree to which the form of the message (affirmative vs. sentence negation vs. performative negation) and the situational context impact judgements of the likelihood of two key facts occurring.

It turned out that when the interview concerned a political competitor, participants judged it as very unlikely that the two key phenomena would occur, and that judgement was similar regardless of whether the utterance came in the form of a affirmative, sentence negation, affirmative with performative verb, or performative negation. It is likely that one set of factors influenced these results in respect of affirmative and another in respect of negations; surely, the context of the utterances also impacted the assessment of the trustworthiness of the messages.

When the utterance of the sender concerning key events came in the form of sentence negation (He does not take bribes, He does not have an alcohol problem) and performative negation (I'm not saying that he takes bribes, I'm not saying that he has an alcohol problem), the message was understood consistently with its content; it was judged unlikely that the key phenomena had in fact occurred. It can be assumed that in the case of negation, the observed objectivity and disinterest of the sender comes into play (he is not attacking a competitor); this may positively influence perceptions of his trustworthiness. This is the source of the low estimation of the like- 
lihood that events negated by the sender had occurred. It should also be pointed out that this judgement was similar in the case of sentence negation and performative negation. It recalls the results in the research described above conducted in the "scenario paradigm"; when expectations were negative concerning the meaning of a comment, the border between sentence negation and performance negation was blurred. I have explained this result through the phenomenon of verbal politeness (see also Colston, 1999). The expectation of negative information may also have been present in this experiment, associated within the context of political competition.

In order to determine whether this context impacted the results recorded, we designed a second experiment in which the sender spoke not about a political rival, but about a party colleague standing for election in another region (the political competition factor was thus eliminated). In this condition, the group of participants who encountered performative negation (e.g. I am not saying that he has an alcohol problem) rated the likelihood greater that the problem occurred than the group which encountered sentence negation (e.g. He doesn't have a problem with alcohol). This could mean firstly that an utterance with performative negation is perceived more as a message about the sender's intentions than a description of a situation, and secondly that it may generate an insinuation effect. The potential insinuation effect is indicated by the fact that there was no significant difference in the assessment of likelihood between affirmative sentences and performative negation. As it turned out, the receivers' judgements of the likelihood that corruption had occurred were similar - regardless of whether the message was He takes bribes or I'm not saying that he takes bribes. Such a result allows us to pose questions about the manipulative effects of performative negation: can its use in the context of polemics with an opponent evoke negative associations among receivers as regards the subject of such an utterance, while at the same time giving an impression of neutrality on the part of the sender?

\section{Summary and conclusions}

Two theoretical contexts influenced the preparation of a plan for the presented studies. First, the theory of speech acts, based on which I have introduced two types of negation: sentence and performative. Second, linguistic pragmatics, which postulates the inferential character of communication consisting in conversational inference, the sender recognising the intentions of the sender, and accounting for context. 
An important objective of the studies was to compare the perception of performative negation and sentence negation. In Study 1, which concerned the semantic relations between those linguistic expressions, it turned out that when the situational context suggests a negative comment by the sender, participants supply similar interpretations of utterances with sentence negation and performative negation. However, if expectations toward the comment are positive, a difference appeared in interpretations of the two types of negation; the indication was that performative negation is perceived to a lesser degree than sentence negation as information about facts, and more about the attitude (disposition, knowledge, intentions) of the sender.

Of interest is that we obtained a similar pattern of results in Study 2, which did not contain a task involving semantic judgement of the forms of messages as a dependent variable. Here the participants assessed the likelihood of the occurrence of the facts spoken of by the sender; that is, they indirectly judged the reliability of the information presented. As it turned out, when the context suggests that one should expect a positive utterance from the sender (the condition of absence of political competition), a clear difference emerged between sentence negation and performance negation. This fact, combined with the lack of difference between affirmative (He takes bribes) and performative negation (I'm not saying that he takes bribes) in judgements about the likelihood of corrupt acts points to the insinuative potential of an utterance with performative negation. Studies on the mechanisms underlying this effect would seem to be an interesting challenge for researchers to tackle.

\section{R E F E R E N C E S}

Austin J. L. (1962). How to do with words. Oxford: Claredon Press.

Clark, H. H. (1976). Semantics and comprehension. The Hague: Mouton.

Clark, H.H. i Chase, W.G. (1972). On the Process of Comparing Sentence against Pictures. Cognitive Psychology, 3 (3), 472-517.

Colston, H. L. (1999). "Not good" is bad, but "not bad" is not good: An analysis of three accounts of negation asymmetry. Discourse Processes, 28, 237-256.

Dahl, Ö. (2011). Typology of negation. In: L. R. Horn (ed.). The Expression of Negation. Berlin: De Gruyter Mouton.

Fodor, J. D., Fodor, J. A., \& Garrett, M. F. (1975). The psychological unreality of semantic representations. Linguistic Inquiry, 6, 515-531.

Lyons, J. (1977). Semantics 2. Cambridge: Cambridge University Press.

Kaup, B., Lüdtke, J. i Zwaan, R. A. (2006). Processing Negated Sentences with Contradictory Predicates: Is a Door That Is Not Open Mentally Closed? Journal of Pragmatics, 38 (7), 1033-1050. 
Maciuszek, J. (2006). Negacja w języku i komunikacji. Kraków: Wydawnictwo UJ.

Maciuszek J. (2013). Don't pay attention to what you see! Negative commands and attention bias. Polish Psychological Bulletin, 44(1), 70-84.

Russell B. (1972). An Inquiry into Meaning and Truth. New York: Routledge.

Searle J.R. (1975). A taxonomy of illocutionary acts. In: K. Gunderson (ed.), Minnesota studies in the philosophy of language, Minneapolis: University of Minnesota Press.

Tian, Y., Breheny, R., \& Ferguson, H. J. (2010). Why we simulate negated information: a dynamic pragmatic account. Quarterly Journal of Experimental Psychology, 63 (12), 2305-2312

Tokarz M. (2006). Argumentacja. Perswazja. Manipulacja. [Argumentation. Persuasion. Manipulation]. Gdańsk: GWP.

Walster E. i Festinger L. (1962). The effectiveness of "overheard" persuasive communications. Journal of Abnormal and Social Psychology, 65, 395-402.

Wason P.C. (1972). In real life, negatives are false. Logique et Analyse, 57-58, 19-38.

Wason P.C. (1965). The context of plausible denial. Journal of verbal Learning and verbal Behavior, 4, 7-11.

Xiang, M., Grove, J., Giannakidou, A. (2016). Semantic and pragmatic processes in the comprehension of negation: An event related potential study of negative polarity sensitivity. Journal of Neurolinguistics, 38, 71-88. 